\title{
Sustainable Technologies? Home Heating and the Co-construction of Gender, Technology and Sustainability
}

By Ursula OfFenberger ANd Julia C. Nentwich of total energy consumption in 2001, households are one of the largest final energy users in the EU. The share of household energy consumption in total energy consumption has increased over the past ten years in almost all countries of the EU. Embracing $70 \%$ of household energy consumption, space heating is by far the biggest energy end-use in households in the EU-15 (EEA 2005). Thus, EU energy policy programs also focus on more sustainable ways of heat energy consumption, energy-efficient technologies playing a fundamental role in reducing energy consumption (European Commission 2006). The further development, market diffusion, and use of technologies based on renewable resources and the home production of heat and electricity in private households, such as pellet heating, solar plants, and the cogeneration of heat and power, are becoming increasingly important for strategies aiming at sustainable development. 
Our research is part of a larger project on sustainable energy consumption in private residential buildings funded by the German Ministry of Research. ${ }^{1}$ The overall focus is on consumer behaviour and buying decisions of energy technologies. Investigating the role of gender for consumer behaviour, our approach not only focuses on the gender of the future users but also on the gendered structures in which buying decisions are embedded, such as gendered work division, logics of market distribution, or symbolic representations of heating. Moving beyond everyday life beliefs in natural differences between women and men, such an approach aims at contributing to a theoretically more profound understanding of consumption patterns.

In this essay we investigate how the market diffusion of such technologies interferes with the production and reproduction of a symbolic gender order. Gender, technology, and sustainability appear as intertwined phenomena, gender binaries being relevant both as a symbolic resource for constructing the materiality of technologies and for discourses on sustainable technologies. We argue that the binary symbolic constructions of both technology and gender contribute to a limited understanding of sustainability as economically driven and change as technological fixes.

\section{INTERRELATIONS OF GENDER AND TECHNOLOGY}

In our empirical analysis, we are looking at the social construction of home heating and the role of technological objects. As interpretative flexibility Eriksson-Zettequist 2007) of technologies is especially visible in the process of diffusion, we are focusing on market distribution as a crucial phase between production and consumption (Schwartz Cowan 1987). The empirical data consist of marketing material and ethnographic observations collected at trade fairs for building and living exhibiting home heating technologies.

Investigating the interrelation between gender and technology, we refer to Faulkner's research on engineering (2000). She suggests a double perspective focusing on both the interactive practices and the symbolic level. This distinction is crucial as gender is made relevant in different ways. While gender practices are full of multiple and more flexible forms of masculinity and femininity (Martin 2003), the binary distinction on the symbolic level has not diminished so far. For instance, Faulkner (2000) identified a number of "highly gendered dichotomies" on the symbolic level, such as people-focused vs. technologyfocused, social vs. technical, emotional connectedness vs. detached objectivity, soft vs. hard technology, concrete vs. abstract, and holistic vs. reductionist. While femininity is commonly associated with the first part of the binary, masculinity is associated with the second. Constructing popular images of science and technology in the context of engineering, the masculine sides of these binaries are highlighted, such as technical, hard, objectivist, and abstract aspects of technology. The more holistic, emotional, people focused and soft sides of science and technology are thereby silenced and hidden. Both sides of the binary are in a hie-rarchical relationship valuing masculine aspects as higher and more important compared to the feminine ones. As we will show in the following paragraphs, gender as a symbolic binary is also made relevant during the market distribution of heating energy technologies for private households.

\section{THE GENDERING OF THE SPATIAL}

ORDER: HEATING AS FACILITY MANAGEMENT OR HOME-MAKING

The symbolic gender order is inscribed into the material structure of technological artefacts as well as into the spatial order of the 
house. Hence, a major difference with regard to heating technology is the positioning of the central heating in the cellar of the house or in the living area. Objects designed for the cellar usually do not assign to common aesthetic criteria (see figure 1). The proportions and the shape of the object shown in figure 1 as well as its grey and metallic red colours rather underline its character as a technological tool than as a stylish feature for modern design-oriented living. In addition, the respective marketing booklets are dominated by technical drawings explaining in full detail the technical performance of the heating system. Thus, they mainly address specialized technical interest and knowledge of their future users (see figure 2).

This is just the opposite case if the central heating is designed for the living area of a house. Here, the exquisite design of the ovens basically hides the technical character for the benefit of aesthetics and an impression of a comfortable way of life (see figure 3 ). In contrast to the central heating in the cellar, the flame is visible here. This visibility plays a central role in turning the heating into an object of comfort and warmth that can be smelled, heard, and seen. The object is smaller than the cellar heating, and the choice of proportions, shape, material, and colours are adapted to modern standards of taste and design.

The central message of the marketing booklets aims at drawing a line between the heating technology and emotional aspects of home heating such as comfort, happiness, and harmonic family life, thus appealing to future users' desire for a relaxing and enjoyable home. Compared to pictures of living rooms with burning stoves, details on technical data play only secondary role for the marketing message (see figure 4 ).

Home heating is either constructed as technology and machine dominated "facility management" taking place in the cellar or as a comfortable life style and people focused "home making", centred around the living area of the house. While the attributes associated with facility management are gendered masculine, home making clearly evokes associations with femininity. The logics of gender, the spatial order and the technological artefact turn out to be intertwined. Furthermore, although Faulkner's distinction between hard and soft does not seem to be relevant in this case, we discovered another well-known gendered dichotomy: the difference between large and small (Goffman 1977). While objects in the cellar are rather large, objects in the living quarters are smaller even if they do not differ with regard to heating capacity.

Finally, both the materiality of the objects and the different ways of advertising them establishes a dichotomy between objectivist rationality, emotional detachment, and abstract theory on the one hand and subjective rationality, emotional connectedness and concrete and holistic approaches on the other: the booklets for the cellar heating are dominated by abstract technical drawings focusing on 'objective' criteria of technical functioning. The firing process takes place invisibly within the burning chamber so that warmth remains an abstract and invisible quality provided by the central heating system. In contrast, the heating in the living quarters enables much more concrete and holistic experience of, and emotional connectedness with, fire and warmth. We can smell, hear and see how the burning process produces warmth. Addressing interest in and concern with comfort, well-being and happiness, the marketing of the heating for the living quarters primarily aims at appealing to future users' subjective rationality and desire for an enjoyable home. Here, the technical character of the object is hidden behind elegant design. In the booklets, technical details play a secondary role compared to the representation of beautiful and stylish living.

In summary, the differences between the two groups of objects appear as different 
gender scripts (Aktich 1992), relating to the gendered spatial order of the house and suggesting that the two heating technologies serve very different purposes. The different gender scripts contribute to naturalize assumptions of technology as a masculine sphere and comfort and well-being as a feminine one.

\section{THE GENDERING OF THE DISCURSIVE ORDER: UNDERSTANDINGS OF SUSTAINABILITY}

Investigating the exhibition of sustainable heat energy technologies at several trade fairs for home building and living, we detected several different discourses of sustainability. While individual economic rationality seemed to be the dominant logic here, others such as intergenerational solidarity and ecological awareness have been present as well although rather marginal. For instance, a major argument we observed in the marketing strategies of both home-making and facility management heating systems was saving costs for the individual household through energy-efficiency and independence from gas and oil. The latter argument was not so much brought forward with regard to the finite nature of fossil fuel supply but rather with regard to global power relations between the Western and the Eastern World comprising the risk of dependence on "Putin and oil sheiks", as a craftsman at one of the booths put it. Arguments of intra- and intergenerational solidarity (saving limited natural resources for next generations and striving for a fairer distribution of resources among different parts of the world) as well as care and responsibility for nature do not take centre stage in the marketing strategies of heat supply technologies building on renewable resources. ${ }^{2}$

Again, reading these different discourses of sustainability from a gender perspective, binary distinctions are very relevant. In the case of individual economic rationality, in- dependence, power, and control seem to form a symbolically masculine discourse as all these values are part of a masculine stereotype. On the other hand, vulnerability, care, responsibility, and solidarity form a symbolically feminine discourse referring to values stereotypically associated with femininity. The two sides of the binary are juxtaposed in a hierarchical way. Investigating the context of market distribution, the discourse of economic calculative rationality seems to overrule and de-legitimize discourses of intra- and intergenerational solidarity as well as care and responsibility for nature as future users of the technologies are rarely addressed with regard to the latter issues.

\section{Conclusion}

Our findings lead to the conclusion that the field of 'sustainable' heating technologies and their market distribution is inseparately intertwined with the production and reproduction of existing symbolic gender orders. Their inscription into technological artefacts leads to the social construction of heating technologies as either technologically advanced tools of 'facility management' or as stylish objects for 'making a comfortable home'. Furthermore, gender scripts of technological artefacts contribute to the appearance of gender differences as natural facts, supporting the perception of gender as natural, unhistorical, stable, and not for change.

Our analysis has shown that gender, technology, and sustainability are intertwined phenomena and should not be treated as separate issues and developments. The interfering logics of gender, technology, and the spatial order of the future location of technologies create what Goffman (1977) has called 'institutional reflexivity' between gender and technology. Associating technology with the masculine or feminine side of the symbolic binary results in severe consequences for the design, the 
marketing, and also the discourses of sustainability made available. While some discourses appear as dominant, others remain marginalized. While this is interesting in itself, the consequences might be rather severe. For instance, the inherent belief in technological fixes which characterizes many strategies aiming towards more sustainable development (cf. Weller 2009) might have one of its roots in the institutional reflexivity between gendered objects, symbolic structures, and hierarchical gender relations. Reflecting upon the intertwinedness of gender, technology, and sustainability will shed light on neglected, silenced, and downplayed aspects of sustainability, which might proof highly relevant for envisioning future strategies for sustainability.

\section{Notes}

1. For more information, see http://www.sozialoekologische-forschung.org/en/1298.php (21.07.2009).

2. The term 'resources' is in itself a marker for a perspective on nature as functional for human interests and without value of itself.

\section{LITERATURE}

- Akrich, Madeleine (1992): "The De-Scription of Technical Objects", in: Bijker, Wiebe E. \& Law, John (eds.): Shaping Technology/Building Society. MIT Press, Cambridge/MA, pp. 205-224.

- EEA (2005): Household consumption and the enviroment. European Enviroment Agency Report, Vol. 11, Copenhagen.
· Eriksson-Zetterquist, Ulla (2007): "Editorial:

Gender and New Technologies", in: Gender, Work and Organization 14/4, pp. 306-311.

- European Commission (2006): Action plan for energy effiency: Realising the potential, COM (2006) 545 final.

. Faulkner, Wendy (2000): "Dualism, Hierarchies and Gender in Engineering", in: Social Studies of Science 30/5, pp. 759-792.

. Goffman, Erving (1977): “The arrangement between the sexes", in: Theory and Society 4, pp. 301-331.

- Hughes, Thomas P.; Bijker, Wiebe E. \& Pinch, Trevor J. (1987, eds.): The Social Construction of Technological Systems. New Directions in the Sociology and History of Technology. Cambridge, MA/London.

- Martin, Patricia (2003): “'Said and done' versus "saying and doing'. Gendering practices, practicing gender at work", in: Gender \& Society 17/3, pp. 342-366.

. Schwartz Cowan, Ruth (1987): “The Consumption Junction: A Proposal for Reseach Strategies in the Sociology of Technoilogy", in: Hughes, Thomas P.; Bijker, Wiebe E. \& Pinch, Trevor J. (eds.): The Social Construction of Technological Systems. New Directions in the Sociology and History of Technology. Cambridge, MA/London, pp. 261280.

- Weller, I: (2009): "Feministische Anmerkung zur Finanzkrise. Technikforschung/-förderung als Antwort auf die Krise: Lösungen für welsche/wessen Probleme?” gena net - gender, umwelt, nachhaltigkeit: pp. 1-5.

Ursula Offenberger, doctoral student

Research Institute for Organizational Psychology, University of St. Gallen, Switzerland.

Julia Nentwich, Dr. rer.soc., senior lecturer Research Institute for Organizational Psychology University of St. Gallen Switzerland 